\title{
Are health conditions and concerns about health effects of smoking predictive of quitting? Findings from the ITC $4 \mathrm{CV}$ Survey (2016-2018)
}

\author{
Lin Li1,2, Ron Borland ${ }^{1,2}$, K. Michael Cummings ${ }^{3,4}$, Ann McNeill5,6, Bryan W. Heckman ${ }^{3}$, Geoffrey T. Fong ${ }^{7,8,9}$, Richard J. \\ $\mathrm{O}^{\prime} \mathrm{Connor}^{10}$, Pete Driezen ${ }^{7,8}$
}

\begin{abstract}
INTRODUCTION Limited research has investigated the relationship between multiple health conditions and subsequent quitting activities at the population level. This study examines whether nine health conditions and concerns related to smoking are predictive of quit attempts and success among those who tried.

METHODS Data came from the International Tobacco Control Four Country Smoking and Vaping Survey conducted in Australia, Canada, England and the US. A total of 3998 daily smokers were surveyed in 2016 and recontacted in 2018. Respondents were asked in 2016 whether they had a medical diagnosis for depression, anxiety, alcohol problems, obesity, chronic pain, diabetes, heart disease, cancer, and chronic lung disease, and whether they had concerns about past/future health effects of smoking. Outcomes were quit attempts and success (having been abstinent for at least one month between surveys).

RESULTS Across all four countries, $44.4 \%$ of smokers tried to quit between the two survey years, and of these $36.8 \%$ were successful. Concerns about past (adjusted odds ratio, $\mathrm{AOR}=1.66,95 \% \mathrm{CI}: 1.32-2.08, \mathrm{p}<0.001$ ) and future effects of smoking (AOR=2.17, 95\% CI: 1.62-2.91, p<0.001) and most health conditions predicted quit attempts, but were mostly unrelated to quit success, with concerns about future effects (AOR=0.59, 95\% CI: 0.35-0.99, $\mathrm{p}<0.05)$, chronic lung conditions $(\mathrm{AOR}=0.56,95 \%$ CI: $0.37-0.86, \mathrm{p}<0.01$ ) and chronic pain (with a trend) being associated with lower success.

CONCLUSIONS Having a major chronic health condition does, generally, motivate making quit attempts, but in some cases it is associated with failure among those who try. More effective cessation support is required for these high priority groups.
\end{abstract}

\section{AFFILIATION}

1 Melbourne Centre for Behaviour Change, School of Psychological Sciences, University of Melbourne, Melbourne, Australia

2 Cancer Council Victoria, Melbourne, Australia 3 Department of Psychiatry and Behavioral Sciences, Medical University of South Carolina, Charleston, United States

4 Hollings Cancer Center, Medical University of South Carolina, Charleston, United States 5 Addiction Department, Institute of Psychiatry, Psychology and Neuroscience, King's College London, London, United Kingdom

6 Shaping Public Health Policies To Reduce Inequalities And Harm (SPECTRUM), the University of Edinburgh, Edinburgh, United Kingdom

7 Department of Psychology, University of Waterloo, Waterloo, Canada

8 School of Public Health and Health Systems, University of Waterloo, Waterloo, Canada 9 Ontario Institute for Cancer Research, Toronto, Canada

10 Department of Health Behavior, Roswell Park Comprehensive Cancer Center, Buffalo, United States

\section{CORRESPONDENCE TO}

Lin Li. Melbourne Centre for Behaviour Change, School of Psychological Sciences, University of Melbourne, Melbourne, VIC 3010, Australia. E-mail: lilin@unimelb.edu.au ORCID ID: https:// orcid.org/0000-0002-4764-1679

\section{KEYWORDS}

risk of tobacco use, health conditions, smoking cessation, longitudinal study

Received: 16 August 2020

Revised: 11 September 2020

Accepted: 11 September 2020

\section{INTRODUCTION}

Many smokers want to stop smoking but find it difficult to do so completely even though they are aware of the possibility of developing health problems 
from smoking. Because of nicotine addiction, some smokers will even persist in smoking after being diagnosed with a serious health problem that can be exacerbated by smoking. Smoking-related physical health conditions such as cancers, chronic obstructive pulmonary disease (COPD) and heart disease have been found to be associated with high rates of quit attempts or greater desire to quit smoking, but have not always translated into higher rates of smoking abstinence ${ }^{1-4}$. For example, smokers with COPD and other pulmonary diseases (e.g. asthma) have been found to have low self-efficacy to quit, are not being referred for intensive cessation treatments, and find it difficult to quit ${ }^{5}$, despite the fact that smoking cessation remains the most effective intervention to reduce or halt lung function decline in $\mathrm{COPD}^{6}$.

Studies have also found that cessation rates are lower for smokers diagnosed with mental health conditions (e.g. depression, anxiety) than the general population of smokers ${ }^{7}$, although they may have made more quit attempts ${ }^{8,9}$. Identified mechanisms that underline persistent smoking among smokers with depression include low positive affect, high negative affect, and cognitive impairment ${ }^{7}$.

The relationship between tobacco smoking and pain is complex with an increasing number of studies attempting to understand the associations between them ${ }^{10-14}$. Chronic pain is defined as pain that lasts longer than six months and is extremely common ${ }^{15}$. Chronic pain conditions have serious negative impacts on quality of life; are associated with mental health conditions such as depression and anxiety, and consumption of greater dosages of prescription opioids; and impact interpersonal relationships and daily activities ${ }^{14,15}$. Chronic pain and tobacco dependence are two highly prevalent and comorbid conditions. The interplay between them has been evident $\mathrm{t}^{13,16,17}$.

It is important to better understand how health problems that a smoker is experiencing are related to motivation to quit and success in remaining abstinent after a quit attempt. At the population level, there are very limited studies that have examined the associations between multiple health conditions and quitting. An earlier cross-sectional study ${ }^{9}$ examined whether having health conditions (including nine physical and mental health conditions) and concerns about the harmful effects of smoking were associated (individually and combined) with making quit attempts and remaining abstinent. The results show that believing smoking had harmed/would harm their health and reported specific health conditions, except for alcohol problems, were positively associated with quit attempts. However, associations between health conditions and planning to quit in the future and use of quitting medications were less consistent ${ }^{9}$. These cross-sectional findings need to be tested longitudinally to see if the same associations apply.

This study uses longitudinal data collected over 18 months to examine how health concerns and reported health conditions predict making quit attempts and success among those who try to quit. Based on previous work, we expect concerns and health conditions, especially those most clearly caused or exacerbated by smoking, to predict making quit attempts but not to predict success in abstaining from cigarettes. Indeed, we hypothesize that some chronic health conditions will be negatively associated with quitting success, as those who continue to smoke despite additional efforts and the motivating influence of a smoking-related illness are likely to represent a particularly dependent subgroup.

\section{METHODS}

\section{Data source and participants}

The data came from Wave 1 (July-November 2016) and Wave 2 (February-July 2018) of the International Tobacco Control Four Country Smoking and Vaping (ITC 4CV) Survey conducted in Australia, Canada, England, and the US. The main sample consisted of the following respondent groups: 1) adult smokers and quitters who responded to previous ITC 4C Surveys (the predecessor of the ITC 4CV Survey) $)^{18}$ and were successfully recontacted online; 2) current smokers and past smokers who had quit smoking in the past 2 years and were newly recruited through online probability-based consumer panels; and 3) newly recruited current users of nicotine vaping products (NVPs). A total of 12294 respondents were present at the 2016 survey (Wave 1), of whom 8201 were current daily smokers. Of these daily smokers in $2016,3998(48.8 \%)$ were recontacted in 2018 (Wave 2) and comprised the sample for the current analysis (Australia: 707; Canada: 1227; England: 
Table 1. Baseline sociodemographic and smoking-related characteristics of daily smokers who were followed up $(n=3998)$ and lost to follow-up ( $n=4203)$ in 2018 in Australia, Canada, England and the United States

\begin{tabular}{|c|c|c|c|c|c|}
\hline \multirow[t]{2}{*}{ Characteristics } & \multicolumn{2}{|c|}{ Followed up } & \multicolumn{2}{|c|}{ Lost to follow-up } & \multirow[t]{2}{*}{$p^{b}$} \\
\hline & $n$ & $\%$ & $n$ & $\%$ & \\
\hline Total & $3998^{\mathrm{a}}$ & 48.8 & $4203^{a}$ & 51.2 & \\
\hline Country & & & & & $<0.001$ \\
\hline Australia & 707 & 56.5 & 544 & 43.5 & \\
\hline Canada & 1227 & 55.3 & 993 & 44.7 & \\
\hline England & 1268 & 44.0 & 1612 & 56.0 & \\
\hline US & 796 & 43.0 & 1054 & 57.0 & \\
\hline Gender & & & & & $<0.001$ \\
\hline Male & 1948 & 46.2 & 2273 & 53.8 & \\
\hline Female & 2050 & 51.5 & 1930 & 48.5 & \\
\hline Age at recruitment (years) & & & & & $<0.001$ \\
\hline $18-24$ & 286 & 21.5 & 1046 & 78.5 & \\
\hline 25-39 & 704 & 36.9 & 1204 & 63.1 & \\
\hline $40-54$ & 1302 & 56.5 & 1003 & 43.5 & \\
\hline$\geq 55$ & 1706 & 64.2 & 950 & 35.8 & \\
\hline Education & & & & & $<0.001$ \\
\hline Low & 1370 & 50.9 & 1324 & 49.2 & \\
\hline Moderate & 1625 & 50.0 & 1627 & 50.0 & \\
\hline High & 970 & 44.8 & 1196 & 55.2 & \\
\hline No information & 33 & 37.1 & 56 & 62.9 & \\
\hline Income & & & & & $<0.01$ \\
\hline Low & 1307 & 50.1 & 1301 & 49.9 & \\
\hline Moderate & 1335 & 49.9 & 1343 & 50.1 & \\
\hline High & 1108 & 45.6 & 1321 & 54.4 & \\
\hline No information & 248 & 51.0 & 238 & 49.0 & \\
\hline Planning to quit & & & & & $<0.001$ \\
\hline Don't know & 506 & 58.1 & 365 & 41.9 & \\
\hline Not planning & 818 & 53.5 & 712 & 46.5 & \\
\hline Beyond 6 months & 1332 & 48.9 & 1394 & 51.1 & \\
\hline Within 6 months & 932 & 45.2 & 1128 & 54.8 & \\
\hline Within 1 month & 408 & 40.9 & 590 & 59.1 & \\
\hline Self-efficacy of quitting & & & & & $<0.001$ \\
\hline Not at all sure & 1395 & 54.9 & 1147 & 45.1 & \\
\hline Slightly sure & 865 & 45.9 & 1018 & 54.1 & \\
\hline Moderately sure/ don't know & 1263 & 48.2 & 1356 & 51.8 & \\
\hline Very sure & 324 & 41.1 & 465 & 58.9 & \\
\hline Extremely sure & 147 & 41.6 & 206 & 58.4 & \\
\hline Heaviness of smoking index (HSI) & 3817 & $\begin{array}{c}\text { Mean }=0.29 \\
\mathrm{SD}=0.86 \\
(-2.33-3.39)\end{array}$ & 3910 & $\begin{array}{c}\text { Mean }=0.11 \\
\mathrm{SD}=0.87 \\
(-2.21-3.15)\end{array}$ & NA \\
\hline
\end{tabular}

a In some analyses, the sample size was smaller than the total due to missing cases. b p-value for chi-squared test. SD: standard deviation. NA: not applicable.

1268; US: 796). Table 1 presents the characteristics more detailed description of sampling methods and of the analytic sample and those lost to follow-up. A original sample size for each country can be found 
elsewhere ${ }^{18-20}$. Study questionnaires and materials were reviewed and provided clearance by Research Ethics Committees at the following institutions: University of Waterloo (Canada, ORE\#20803/30570, ORE\#21609/30878), King's College London, UK (RESCM-17/18-2240), Cancer Council Victoria, Australia (HREC1603), University of Queensland, Australia (2016000330/HREC1603), and Medical University of South Carolina (waived due to minimal risk). All participants gave informed consent ${ }^{18-20}$.

\section{Measures}

Self-reported health conditions and concerns related to smoking.

Respondents were asked in the 2016 survey whether they were currently being treated for, or had been diagnosed (current diagnosis) with, the following nine health conditions that are associated with smoking cigarettes: depression, anxiety, alcohol problems, severe obesity, chronic pain, diabetes, heart disease, cancer (excluding non-melanoma skin cancer), and chronic lung disease (e.g. chronic bronchitis and emphysema). Their answers were coded as 'yes' vs 'no/don't know'. In England, respondents were asked about lung cancer and other types of cancer separately; and, instead of chronic lung disease, were asked about four specific conditions: asthma, emphysema, chronic bronchitis or tuberculosis. Reporting any of the cancers or lung diseases was coded as having the general condition. We also conducted supplementary analyses on a composite of having at least one of the nine health conditions ('any' vs 'none').

In addition, participants were asked: 'To what extent, if at all, has smoking cigarettes damaged your heath?' and 'How worried are you, if at all, that smoking cigarettes will damage your health in the future?'. The response options for both were: 'not at all', 'just a little', 'a fair amount/moderately', 'a great deal', and 'don't know'. Responses were recoded into 'yes, at least moderately' vs all lesser responses and 'don't know', as have been done in previously published research ${ }^{21}$.

\section{Outcome measures}

The main outcomes assessed in this study were: 1) quit attempts, defined as having made at least one quit attempt between survey waves by asking smokers 'How many times have you tried to quit since last survey date?' (at least 1 attempt vs no attempt/don't know), or if they were currently abstinent at the 2018 survey; and 2) quit success, defined as having been abstinent for at least one month at any point between the two survey waves among those who tried to quit between survey waves.

\section{Covariates}

All covariates were measured in the 2016 survey wave. Demographic measures were gender (male, female) and age $(18-24,25-39,40-54, \geq 55$ years). Due to the differences in economic development and educational systems across countries, only relative levels of income and education were used. A 'low' level of education referred to those who completed high school or less in Canada, the US, and Australia, or secondary/ vocational or less in England; 'moderate' meant community college/trade/technical school/some university (no degree) in Canada and the US, college/ university (no degree) in England, or technical/ trade/some university (no degree) in Australia; and 'high' referred to those who completed university or postgraduate studies in all countries. Household income per year was also grouped into 'low' $(<\$ 30000$ in US, \$45000 in Australia and Canada [countryspecific dollars], $£ 15000$ in England), 'moderate' (\$30000-\$59999 in US, \$45000-\$74999 in Australia and Canada, £15000-£39999 in England), and 'high' categories ( $\geq \$ 60000$ in US, $\geq \$ 75000$ in Australia and Canada, $\geq £ 40000$ in England), and 'not reported'.

Nicotine dependence was measured using the continuous version of the Heaviness of Smoking Index (HSI), which subtracts the natural log of time to first cigarette in minutes from the square root of cigarettes per day ${ }^{22}$. Respondents were asked about their intention/planning to quit via the following question: 'are you planning to quit smoking?'. Response options were 'within the next month', 'within the next 6 months', 'sometime in the future, beyond 6 months', 'not planning to quit' and 'don't know'. Self-efficacy of quitting was assessed by asking: "if you decided to give up smoking completely in the next 6 months, how sure are you that you would succeed?'. Response options were 'not at all sure', 'slightly sure', 'moderately sure/ don't know', 'very sure', and 'extremely sure'.

\section{Data analysis}

Descriptive statistics were used to examine differences 
in sociodemographic/smoking-related characteristics in subgroups. The associations between smoking cessation outcomes (i.e. quit attempts and quit success) and reporting of health conditions and concerns related to smoking (predictor variables) were examined using logistic regression. Bivariate logistic regression models were first used to examine the association between an outcome variable and each individual health condition/concern. Multivariable logistic regression models were then employed to further examine the association (with adjusted odds ratio) between the quit outcome and individual health condition/concern (or a composite of the conditions), controlling for sociodemographic characteristics (i.e. gender, age, education and country) and health concerns; and finally, for quit success, logistic regression models are reported for longitudinal analyses, but we also ran them with the best longitudinal weights we could compute and note any meaningful differences in the text. In all analyses, a $\mathrm{p}<0.05$ was considered statistically significant. All analyses were conducted using Stata Version 16.1.

\section{RESULTS}

\section{Sample characteristics}

Table 1 presents the baseline characteristics of the samples. A total of 3998 respondents were recontacted at Wave 2 survey (out of 8201 daily smokers from Wave 1). Females, older respondents, those without a plan to quit smoking, and those in Australia and Canada compared to those in the US and England, were more likely to be followed up.

\section{The relationship between self-reported health conditions/concerns and subsequent quitting activities}

Across all four countries, $44.4 \%$ of smokers (the weighted point estimate: $45.1 \%$ ) reported trying to quit between the two survey waves. As shown in Table 2 , over $89 \%$ reported having concerns about health effects of smoking (both in the past and future), and considerable percentages of respondents had depression (20\%), anxiety (18\%), and chronic pain (13\%). Comparatively smaller percentages of respondents reported other health conditions.

Table 2. Relationship between health conditions/concerns and subsequent quit attempts between Wave 1 (2016) and Wave 2 (2018) among daily smokers $\left(n=3998^{a}\right)$ in Australia, Canada, England and the United States

\begin{tabular}{|c|c|c|c|c|c|}
\hline Condition or concern (Yes) & With condition ${ }^{b}$ & $\begin{array}{l}\text { Made quit } \\
\text { attempts } \\
\%(95 \% \text { CI })\end{array}$ & $\begin{array}{c}\text { Unadjusted } \\
\text { bivariate model vs } \\
\text { without concern/ } \\
\text { condition } \\
\text { OR }(95 \% \text { CI })\end{array}$ & $\begin{array}{c}\text { Adjusted Model } I^{c} \\
\text { VS without } \\
\text { concern/condition } \\
\text { OR }(95 \% \text { CI })\end{array}$ & $\begin{array}{c}\text { Adjusted Model } 2^{d} \\
\text { VS without } \\
\text { concern/condition } \\
\text { OR }(95 \% \text { CI })\end{array}$ \\
\hline $\begin{array}{l}\text { Concerns about past health } \\
\text { effects of smoking }\left(n=3549^{\text {a }}\right)\end{array}$ & $88.9(88.0-89.9)$ & $46.1(44.4-47.7)$ & $1.85(1.49-2.28)^{* * * e}$ & $1.96(1.58-2.43)^{* * *}$ & $1.66(1.32-2.08)^{* * *}$ \\
\hline $\begin{array}{l}\text { Concerns about future health } \\
\text { effects }(n=3703)\end{array}$ & $92.8(92.0-93.6)$ & $46.0(44.4-47.6)$ & $2.69(2.04-3.56)^{* * *}$ & $2.59(1.96-3.44)^{* * *}$ & $2.17(1.62-2.91)^{* * *}$ \\
\hline Depression $(n=810)$ & $20.4(19.2-21.7)$ & $50.3(46.8-53.7)$ & $1.33(1.14-1.56)^{* * *}$ & $1.25(1.06-1.46)^{* *}$ & $1.20(1.02-1.41)^{*}$ \\
\hline Anxiety $(n=720)$ & $18.2(16.9-19.4)$ & $51.1(47.5-54.8)$ & $1.38(1.17-1.62)^{* * *}$ & $1.19(1.01-1.42)^{*}$ & $1.14(0.96-1.35)$ \\
\hline Alcohol problems $(n=125)$ & $3.2(2.6-3.7)$ & $47.2(38.4-55.9)$ & $1.11(.78-1.59)$ & $1.07(0.74-1.54)$ & $1.00(0.69-1.45)$ \\
\hline Severe obesity $(n=110)$ & $2.8(2.2-3.3)$ & $57.3(48.0-66.5)$ & $1.69(1.15-2.48)^{* *}$ & $1.44(0.97-2.13)$ & $1.42(0.95-2.10)$ \\
\hline Chronic pain $(n=522)$ & $13.2(12.1-14.2)$ & $49.0(44.8-53.3)$ & $1.23(1.02-1.48)^{*}$ & $1.29(1.06-1.55)^{* *}$ & $1.27(1.05-1.54)^{*}$ \\
\hline Diabetes $(n=355)$ & $8.9(8.1-9.8)$ & $44.5(39.3-49.7)$ & $0.99(0.80-1.24)$ & $1.14(0.91-1.43)$ & $1.14(0.91-1.43)$ \\
\hline Heart disease $(n=185)$ & $4.7(4.0-5.3)$ & $49.2(42.0-56.4)$ & $1.21(0.90-1.63)$ & $1.43(1.06-1.95)^{*}$ & $1.34(0.98-1.82)$ \\
\hline Cancer $(n=86)$ & $2.2(1.7-2.6)$ & $46.5(36.0-57.0)$ & $1.09(0.71-1.67)$ & $1.25(0.81-1.93)$ & $1.21(0.78-1.88)$ \\
\hline Chronic lung disease $(n=275)$ & $6.9(6.1-7.7)$ & $48.4(42.4-54.3)$ & $1.19(0.93-1.52)$ & $1.41(1.09-1.82)^{* *}$ & $1.32(1.02-1.70)^{*}$ \\
\hline $\begin{array}{l}\text { Having any of the above nine } \\
\text { conditions }(n=1754)\end{array}$ & $44.3(42.7-45.8)$ & $49.7(47.3-52.0)$ & $1.45(1.28-1.64)^{* * *}$ & $1.44(1.27-1.63)^{* * *}$ & $1.39(1.21-1.58)^{* * *}$ \\
\hline
\end{tabular}

a In some analyses the sample size was smaller than the total due to missing cases. $\mathrm{b}$ The percentage with a reported health condition or concern. OR: odds ratio. Cl: confidence interval. c Adjusted Model 1: Adjusted for gender, age, education and country. d In addition to those characteristics that were adjusted in Model 1, Model 2 also controlled for concerns for past and future health effects of smoking. e Reference value was for those without the health concern/condition, and this applies to all conditions. ${ }^{*}$ Significant at $\mathrm{p}<0.05 ;{ }^{* *} \mathrm{p}<0.01 ;{ }^{* * *} \mathrm{p}<0.001$. 
Both concerns about the health effects of smoking and a number of health conditions reported at Wave 1 were associated with an increased likelihood of making a quit attempt between waves, after controlling for sociodemographic characteristics (adjusted Model 1, Table 2). After further controlling for health concerns (adjusted Model 2, Table 2), the association between reported health problems and making a quit attempt remained positive with the exception of those reporting anxiety and heart disease.

As shown in Table 2, compared to those without any of the nine health conditions that we assessed at baseline (i.e. with ' 0 ' condition), smokers with at least one of the conditions $(1+$ condition $)$ were more likely to make quit attempts $(49.7 \%$ vs $40.5 \%$; $\mathrm{AOR}=1.39,95 \%$ CI: $1.21-1.58, \mathrm{p}<0.001)$, after controlling for sociodemographic characteristics and general concern for health.

It is notable that both concern measures have predictive power in Model 2 and adding them both had little effect on the predictive power of the individual or the collective measures of health conditions.

Of the 1775 respondents who made quit attempts between the two survey waves, 1724 had their quit success status determined, with 634 (36.8\%) having achieved at least 1-month abstinence between survey waves. Unlike for quit attempts, where all the health concerns and health problems were associated with attempts, we did not find any positive associations with quitting success, which was no different between those having one or more of the nine conditions and those without $(35.6 \%$ vs $37.7 \%$; AOR $=0.94,95 \%$ CI: $0.76-1.15, \mathrm{p}>0.05)$ (Table 3). Quitting success was negatively associated with having concerns about health effects in the future, chronic pain and chronic lung disease, after controlling for sociodemographic characteristics (Adjusted Model 1, Table 3). When we also controlled for nicotine dependence and self-efficacy to quit, the negative association remained essentially the same for concerns about health effects in the future $(36.2 \%$ vs $49.3 \%$; AOR $=0.59$, 95\% CI: $0.35-$ $0.999, p=0.050)$ and chronic lung disease $(26.7 \%$

Table 3. Relationship between health conditions/concerns and quit success among those who made quit attempts $\left(n=1775^{a}\right)$ between Wave 1 (2016) and Wave 2 (2018) in Australia, Canada, England and the United States

\begin{tabular}{|c|c|c|c|c|c|}
\hline Condition or concern (Yes) & $\%(95 \%$ CI $)$ & $\begin{array}{c}\text { Quit for } 1 \text { month } \\
\text { or longer between } \\
\text { waves } \\
\%(95 \% \text { CI })\end{array}$ & $\begin{array}{l}\text { Unadjusted } \\
\text { bivariate model vs } \\
\text { without concern/ } \\
\text { condition } \\
\text { OR }(95 \% \text { CI })\end{array}$ & $\begin{array}{c}\text { Adjusted Model I } \\
\text { VS without } \\
\text { concern/condition } \\
\text { OR }(95 \% \text { CI })\end{array}$ & $\begin{array}{c}\text { Adjusted Model } 2^{d} \\
\text { VS without } \\
\text { concern/condition } \\
\text { OR }(95 \% \text { CI })\end{array}$ \\
\hline $\begin{array}{l}\text { Concerns about past health } \\
\text { effects of smoking }\left(n=1634^{\text {a }}\right)\end{array}$ & $92.2(90.9-93.4)$ & $36.2(33.9-38.6)$ & $0.73(0.51-1.05)^{e}$ & $0.71(0.50-1.02)$ & $0.73(0.51-1.06)$ \\
\hline $\begin{array}{l}\text { Concerns about future health } \\
\text { effects }(n=1704)\end{array}$ & 96.1 (95.2-97.0) & $36.2(33.9-38.5)$ & $0.58(0.36-0.94)^{*}$ & $0.57(0.35-0.93)^{*}$ & $0.59(0.35-0.999)^{*}$ \\
\hline Depression $(n=407)$ & $23.1(21.1-25.0)$ & $36.0(31.3-40.8)$ & $0.96(0.76-1.22)$ & $0.99(0.78-1.25)$ & $0.98(0.76-1.25)$ \\
\hline Anxiety $(n=368)$ & $20.8(18.9-22.7)$ & $38.0(33.0-43.0)$ & $1.07(0.84-1.36)$ & $1.12(0.87-1.43)$ & $1.12(0.86-1.45)$ \\
\hline Alcohol problems $(n=59)$ & $3.3(2.5-4.2)$ & $31.6(19.5-43.6)$ & $0.79(0.44-1.39)$ & $0.82(0.46-1.45)$ & $0.86(0.48-1.53)$ \\
\hline Severe obesity ( $n=63$ ) & $3.6(2.7-4.4)$ & $34.4(22.5-46.3)$ & $0.90(0.53-1.54)$ & $0.92(0.53-1.58)$ & $1.15(0.66-2.01)$ \\
\hline Chronic pain $(n=256)$ & $14.5(12.9-16.1)$ & $30.9(25.2-36.7)$ & $0.74(0.56-0.99)^{*}$ & $0.72(0.54-0.97)^{*}$ & $0.74(0.58-1.01)$ \\
\hline Diabetes $(n=158)$ & $9.0(7.6-10.2)$ & $33.3(25.8-40.9)$ & $0.85(0.59-1.21)$ & $0.84(0.58-1.21)$ & $0.86(0.59-1.24)$ \\
\hline Heart disease $(n=91)$ & $5.2(4.1-6.2)$ & $36.7(26.7-46.6)$ & $0.99(0.64-1.55)$ & $0.99(0.63-1.56)$ & $1.06(0.66-1.68)$ \\
\hline Cancer $(n=40)$ & $2.3(1.6-2.9)$ & $28.2(14.1-42.3)$ & $0.67(0.33-1.35)$ & $0.67(0.32-1.36)$ & $0.71(0.34-1.47)$ \\
\hline Chronic lung disease $(n=133)$ & $7.5(6.3-8.7)$ & $26.7(19.1-34.3)$ & $0.61(0.40-0.90)^{*}$ & $0.57(0.38-0.86)^{* *}$ & $0.56(0.37-0.86)^{* *}$ \\
\hline $\begin{array}{l}\text { Having any of the above nine } \\
\text { condition }(n=871)\end{array}$ & $49.3(47.0-51.6)$ & $35.6(32.6-39.0)$ & $0.91(0.75-1.11)$ & $0.92(0.76-1.13)$ & $0.94(0.76-1.15)$ \\
\hline
\end{tabular}

a In some analyses the sample size was smaller than the total due to missing cases. b The percentage with a reported health condition or concern among those who made quit attempts. OR: odds ratio. Cl: confidence interval. c Adjusted Model 1: Adjusted for gender, age, education and country. d Adjusted Model 2: Adjusted for sociodemographic characteristics as well as self-efficacy and nicotine dependence. e Reference value was for those without the health concern/condition, and this applies to all conditions. ${ }^{*}$ Significant at $p<0.05 ;{ }^{* *} p<0.01 ;{ }^{* * *} p<0.001$. 
vs $37.6 \%$; $\mathrm{AOR}=0.56,95 \%$ CI: $0.37-0.86, \mathrm{p}<0.01$ ); and there was a trend for chronic pain to also be associated with relapse $(\mathrm{p}=0.055)$ (Adjusted Model 2 , Table 3). When we ran the analysis with rescaled longitudinal weights, both chronic pain and chronic lung disease were negatively associated with quit success (Supplementary file, Table S1).

\section{DISCUSSION}

Concerns about past and future health effects of smoking, and most individual health conditions, predicted making quit attempts, but were mostly unrelated to quitting success, with relationships with worry about future health, chronic lung conditions and perhaps pain associated with lower success.

These results are consistent with prior findings ${ }^{5,23,24}$ and underscore evidence of motivation to quit being unrelated to success in smoking abstinence ${ }^{8,25,26}$. While we expected both conditions and concerns to be positively associated with making quit attempts, we were surprised that the relationship with health conditions was largely independent of both believing that smoking has harmed their health and worrying that it will in future, with the last two having independent but attenuated relationships. It suggests that the specific concerns related to specific conditions are not fully integrated into overall concerns.

Contrary to simple motivation-based theories, future health concern was associated with lower success rates as were having chronic lung disease and chronic pain. It is more consistent with our hypothesis that highly motivated to quit smokers who are still smoking are overall more dependent $\mathrm{t}^{25}$. The negative association between chronic lung disease and quit success is discouraging, given the importance of smoking cessation for those suffering from chronic lung disease ${ }^{27}$. There is evidence that smokers with COPD have specific features that may make it harder for them to quit ${ }^{4,28}$. Smokers with COPD score higher on the Fagerström Test for Nicotine Dependence (FTND) and the number of cigarettes smoked daily is significantly higher compared with smokers without $\mathrm{COPD}^{4,28}$. We observed a similar negative association with quitting success in patients reporting chronic pain. It is possible that smoking and perhaps nicotine administration may help these patients cope with their pain ${ }^{12,14}$. It is also possible that smokers with chronic pain are also using other drugs such as opioids and cannabis that may impair their ability to sustain quitting smoking entirely. Animal studies have yielded consistent support for direct pain-inhibitory effects of nicotine and tobacco, but results from human studies are much less consistent ${ }^{13}$. As mentioned earlier, an increasing number of studies have been dedicated to understanding the relationship between tobacco smoking and pain ${ }^{10-14}$. Overall, smoking prevalence among chronic pain patients is more than twice in the general population ${ }^{13,16,17}$. Individuals with a lifetime history of chronic neck pain or chronic back pain are 1.5 times more likely to be current smokers and 2.4 times more likely to be nicotine dependent compared to individuals without chronic pain ${ }^{23,24}$. The relationship between pain and smoking is bidirectional: not only does pain seem to increase rates and intensity of smoking, but smoking has a major impact on pain as well ${ }^{17}$. Smoking is associated with a higher incidence of pain and worse pain severity ${ }^{10,29}$. Data from a British national survey demonstrates prevalence ratios of 1.1 to 1.3 for incident musculoskeletal pain among smokers compared to non-smokers ${ }^{29}$. It is not clear whether this is a causal relationship or reflects a possibly ineffective self-medication effect. Current smokers are also found to be more likely than non-smokers and ex-smokers to use narcotics and other analgesic drugs in an attempt to alleviate that pain ${ }^{30,31}$. Having chronic pain is also associated with an increased likelihood of daily use of nicotine vaping products ${ }^{21}$. Pain intensity is related to more severe smoking behaviour and nicotine dependence ${ }^{11,32}$, and quitting (nicotine withdrawal) could result in increased pain (subjective and objective indices) ${ }^{33}$, which in turn may deter smokers from trying to quit and remaining abstinent. Smokers with chronic pain tend to experience lower confidence and greater difficulty when attempting to quit, and have a reduced likelihood to achieve abstinence ${ }^{34}$, highlighting the barriers (e.g. loss of reward, withdrawal, discomfort, stress) to smoking cessation and specific needs (e.g. combination of counselling and pharmacological treatment) for this particular subgroup of tobacco smokers. 


\section{Strengths and limitations}

There are several limitations to this study that need to be acknowledged. First, this study relied on selfreported behavioural measures without biochemical validation; however, we cannot see any reason why there would be differential misreporting among the participants. Second, as we mentioned earlier, some participants were smokers and quitters who had responded to previous ITC 4C Survey and, compared to newly recruited participants, they may have had differential memory effects in reporting on quitting. To overcome this, we did ask about more recent quit attempts (in the past 12 months) in our survey, but we could not completely overcome the memory effect issue. Third, the time of onset and severity/complexity of the health conditions were not assessed (e.g. chronic pain); if our interpretation of the findings is correct, we might expect stronger negative relationships between quit success and chronic diseases the longer they have persisted. In addition, we have obviously relied on self-diagnosis of problems and these may differ from formal diagnoses, but again we cannot see any reason this would differentially affect results. We would expect knowledge a smoker has a condition that may be caused or worsened by their smoking would be a critical element in motivating extra action. In future, it would be useful to look at recency of acquiring health conditions, as onset of chronic conditions linked to smoking should be a potent motivator of quitting and that, if our interpretation is correct, after some time those who want to quit, and can, will have done so, so among the newly diagnosed we might expect increased success. The sample although large overall, only had small numbers of cases with some conditions (e.g. cancer), so power to find effects of meaningful size for those conditions is limited. Finally, there was differential loss to followup, meaning lost cases cannot be considered missing at random, so some caution is required in generalizing to the overall population.

Strengths of the study include the longitudinal design of the study, multi-country data and reasonably large sample that allowed us to identify associations between health conditions/concerns and outcomes of interest. In itself, our results say nothing strong about possible causation. However, the longitudinal design helped increase the capacity to explain effect in terms of possible causal relationships where causal associations have been established in other work; so for example, we can be confident the increased quitting attempts, associated with lung disease at least, are partly a result of factors associated with having the condition.

We would expect that all or nearly all of the respondents with chronic conditions to have those conditions managed by health professionals. Research shows that quitting rates remain low among many patients with COPD and other chronic conditions, despite being aware of the specific link between their condition and smoking ${ }^{5}$. An earlier cross-sectional study ${ }^{9}$ showed that levels of use of the strongest possible cessation help was disappointingly low. Coupled with our new findings, it suggests a pressing need to find better ways to support smokers with smoking-related conditions to use the strongest possible tools to maximize their capacity to quit successfully. More effective cessation support needs to be accompanied by a much stronger suite of measures that will substantially reduce supply and demand for tobacco products.

\section{CONCLUSIONS}

Having a major chronic health condition does, generally, motivate making quit attempts, but in some cases it is associated with failure among those who try. More effective cessation support is required for these high priority groups.

\section{REFERENCES}

1. Gritz ER. Smoking and smoking cessation in cancer patients. Br J Addict. 1991;86(5):549-554. doi:10.1111/j.1360-0443.1991.tb01806.x

2. McBride CM, Emmons KM, Lipkus IM. Understanding the potential of teachable moments: the case of smoking cessation. Health Educ Res. 2003;18(2):156-170. doi:10.1093/her/18.2.156

3. Hermanson B, Omenn GS, Kronmal RA, Gersh BJ. Beneficial six-year outcome of smoking cessation in older men and women with coronary artery disease. Results from the CASS registry. N Engl J Med. 1988;319(21):13651369. doi:10.1056/nejm198811243192101

4. Shahab L, Jarvis MJ, Britton J, West R. Prevalence, diagnosis and relation to tobacco dependence of chronic obstructive pulmonary disease in a nationally representative population sample. Thorax. 2006;61(12):1043-1047. doi:10.1136/thx.2006.064410

5. Jiménez-Ruiz CA, Andreas S, Lewis KE, et al. Statement on smoking cessation in COPD and other 
pulmonary diseases and in smokers with comorbidities who find it difficult to quit. 2015;46(1):61-79. doi:10.1183/09031936.00092614

6. Vogelmeier CF, Criner GJ, Martinez FJ, et al. Global Strategy for the Diagnosis, Management, and Prevention of Chronic Obstructive Lung Disease 2017 Report. GOLD Executive Summary. Am J Respir Crit Care Med. 2017;195(5):557-582. doi:10.1164/rccm.201701-0218pp

7. Mathew AR, Hogarth L, Leventhal AM, Cook JW, Hitsman B. Cigarette smoking and depression comorbidity: systematic review and proposed theoretical model. Addiction. 2017;112(3):401-412. doi:10.1111/add.13604

8. Cooper J, Borland R, McKee SA, Yong H-H, Dugué P-A. Depression motivates quit attempts but predicts relapse: differential findings for gender from the International Tobacco Control Study. Addiction. 2016;111(8):14381447. doi:10.1111/add.13290

9. Li L, Borland R, O'Connor R, et al. The association between smokers' self-reported health problems and quitting: Findings from ITC Four Country Smoking and Vaping Wave 1 Survey. Tob Prev Cessation. 2019;5(December):1-11. doi:10.18332/tpc/114085

10. Khan JS, Hah JM, Mackey SC. Effects of smoking on patients with chronic pain: a propensity-weighted analysis on the Collaborative Health Outcomes Information Registry. Pain. 2019;160(10):2374-2379. doi:10.1097/j.pain.0000000000001631

11. Bakhshaie J, Ditre JW, Langdon KJ, Asmundson GJ, Paulus DJ, Zvolensky MJ. Pain intensity and smoking behavior among treatment seeking smokers. Psychiatry Res. 2016;237:67-71. doi:10.1016/j.psychres.2016.01.073

12. Ditre JW, Zale EL, Heckman BW, Hendricks PS. A measure of perceived pain and tobacco smoking interrelations: pilot validation of the pain and smoking inventory. Cogn Behav Ther. 2017;46(4):339-351. doi:10.1080/16506073.2016.1256347

13. Ditre JW, Brandon TH, Zale EL, Meagher MM. Pain, nicotine, and smoking: research findings and mechanistic considerations. Psychol Bull. 2011;137(6):1065-1093. doi:10.1037/a0025544

14. Hooten WM, Townsend CO, Bruce BK, et al. Effects of smoking status on immediate treatment outcomes of multidisciplinary pain rehabilitation. Pain Med. 2009;10(2):347-355. doi:10.1111/j.1526-4637.2008.00494.x

15. Nugent B, Ayuso E, Zinn R, al e. Conference Report: Opioid and Nicotine Use, Dependence, and Recovery: Influences of Sex and Gender. In: Opioid and Nicotine: Influences of Sex and Gender. Atlanda, GA: Office of Women's Health, US Food and Drug Administration; 2019. https://www.fda.gov/media/129931/download. Accessed September 11, 2020.

16. Fishbain DA, Lewis JE, Bruns D, Meyer LJ, Gao J, Disorbio JM. The prevalence of smokers within chronic pain patients and highest pain levels versus comparison groups. Pain Med. 2013;14(3):403-416. doi:10.1111/pme.12024

17. Jareczek FJ. Mechanistic bases for the adverse interaction of nicotine and chronic pain. Iowa, IA: University of Iowa; 2018.

18. Thompson M, Fong G, Hammond D, et al. Methods of the International Tobacco Control (ITC) Four Country Survey. Tob Control. 2006;15(Suppl III):iii12-18. doi:10.1136/tc.2005.013870

19. Thompson ME, Fong GT, Boudreau C, et al. Methods of the ITC Four Country Smoking and Vaping Survey, wave 1 (2016). Addiction. 2019;114(Suppl 1):6-14. doi:10.1111/add.14528

20. ITC Project. ITC Four Country Smoking and Vaping Survey, Wave 2 (2018) Technical Report. Waterloo, ON, Charleston, SC, Melbourne, Australia, Brisbane, Australia, London, United Kingdom: University of Waterloo, Medical University of South Carolina, Cancer Council Victoria, University of Queensland, King's College London; 2020. https://itcproject.s3.amazonaws.com/ uploads/documents/4CV2_Technical_Report_15Jan202. pdf. Accessed September 11, 2020.

21. Li L, Borland R, O'Connor RJ, et al. How Are SelfReported Physical and Mental Health Conditions Related to Vaping Activities among Smokers and Quitters: Findings from the ITC Four Country Smoking and Vaping Wave 1 Survey. Int J Environ Res Public Health. 2019;16(8):1412. doi:10.3390/ijerph16081412

22. Borland R, Yong H, O'Connor R, Hyland A, Thompson $\mathrm{M}$. The reliability and predictive validity of the Heaviness of Smoking Index and its two components: Findings from the International Tobacco Control Four-Country study. Nicotine Tob Res. 2010;12(Suppl 1):S45-S50. doi:10.1093/ntr/ntq038

23. Zvolensky MJ, McMillan KA, Gonzalez A, Asmundson GJ. Chronic musculoskeletal pain and cigarette smoking among a representative sample of Canadian adolescents and adults. Addict Behav. 2010;35(11):1008-1012. doi:10.1016/j.addbeh.2010.06.019

24. Zvolensky MJ, McMillan KA, Gonzalez A, Asmundson GJ. Chronic musculoskeletal pain and cigarette smoking among a representative sample of Canadian adolescents and adults. Addict Behav. 2010;35(11):1008-1012. doi:10.1016/j.addbeh.2010.06.019

25. Borland R, Yong HH, Balmford J, et al. Motivational factors predict quit attempts but not maintenance of smoking cessation: Findings from the International Tobacco Control Four country project. Nicotine Tob Res. 2010;12:S4-S11. doi:10.1093/ntr/ntq050

26. Ditre JW, Heckman BW, Butts EA, Brandon TH. Effects of expectancies and coping on pain-induced motivation to smoke. J Abnorm Psychol. 2010;119(3):524-533. doi:10.1037/a0019568

27. Eisner MD, Yelin EH, Katz PP, Shiboski SC, Henke J, Blanc PD. Predictors of cigarette smoking and smoking cessation among adults with asthma. Am J Public Health. 
2000;90(8):1307-1311. doi:10.2105/ajph.90.8.1307

28. Jiménez-Ruiz CA, Masa F, Miravitlles M, et al. Smoking characteristics: differences in attitudes and dependence between healthy smokers and smokers with COPD. Chest. 2001;119(5):1365-1370. doi:10.1378/chest.119.5.1365

29. Palmer KT, Syddall H, Cooper C, Coggon D. Smoking and musculoskeletal disorders: findings from a British national survey. Ann Rheum Dis. 2003;62(1):33-36. doi:10.1136/ard.62.1.33

30. Chapman SLC, Wu LT. Associations between cigarette smoking and pain among veterans. Epidemiol Rev. 2015;37(1):86-102. doi:10.1093/epirev/mxu008

31. Plesner K, Jensen HI, Højsted J. Smoking history, nicotine dependence and opioid use in patients with chronic non-malignant pain. Acta Anaesthesiol Scand. 2016;60(7):988-994. doi:10.1111/aas.12741

32. Ditre JW, Zale EL, LaRowe LR, Kosiba JD, De Vita MJ. Nicotine deprivation increases pain intensity, neurogenic inflammation, and mechanical hyperalgesia among daily tobacco smokers. J Abnorm Psychol. 2018;127(6):578589. doi:10.1037/abn0000353

33. Ditre JW, Kosiba JD, Zale EL, Zvolensky MJ, Maisto SA. Chronic Pain Status, Nicotine Withdrawal, and Expectancies for Smoking Cessation Among Lighter Smokers. Ann Behav Med. 2016;50(3):427-435. doi:10.1007/s12160-016-9769-9

34. Ditre JW, Heckman BW, LaRowe LR, Powers JM. Pain Status as a Predictor of Smoking Cessation Initiation, Lapse, and Relapse. Nicotine Tob Res. 2020. doi:10.1093/ntr/ntaa111

\section{ACKNOWLEDGEMENTS}

The authors would like to thank Haoxiang Li and Anne C.K. Quah for their assistance in preparing the tables and editing early drafts of the manuscript. The lead author presented some of the results and received valuable feedback at the 2019 Inaugural SRNT-Oceania Conference in Sydney in October 2019. The authors thank other members of the ITC 4CV Survey team for their support. We are grateful to the anonymous reviewers who provided useful suggestions on an earlier draft of the manuscript.

\section{CONFLICTS OF INTEREST}

The authors have each completed and submitted an ICMJE form for disclosure of potential conflicts of interest. The authors declare that they have no competing interests, financial or otherwise, related to the current work. K. M. Cummings has received payment as a consultant to Pfizer, Inc., for service on an external advisory panel to assess ways to improve smoking cessation delivery in healthcare settings, and has served as paid expert witness in litigation filed against cigarette manufacturers. G. T. Fong has served as an expert witness on behalf of governments in litigation involving the tobacco industry.

\section{FUNDING}

This study was supported by grants from the US National Cancer Institute (P01 CA200512), the Canadian Institutes of Health Research (FDN-148477), and by the National Health and Medical Research Council of Australia (APP 1106451). GTF was supported by a Senior Investigator Grant from the Ontario Institute for Cancer Research.

\section{AUTHORS' CONTRIBUTIONS}

All authors made significant contributions to the work reported. Conceptualization: LL, RB, KMC, GTF and AM; methodology: LL, RB, RJO, $\mathrm{BWH}$ and $\mathrm{PD}$; formal analysis: $\mathrm{LL}$ and $\mathrm{RB}$; writing of original draft: $L L$ and $\mathrm{RB}$; writing, final review and editing: All authors.

PROVENANCE AND PEER REVIEW

Not commissioned; externally peer reviewed. 